\title{
Evaluation of vitrectomy combined preoperative intravitreal ranibizumab and postoperative intravitreal triamcinolone acetonide for proliferative diabetic retinopathy
}

\section{Zhaodong Du}

Qingdao University Medical College https://orcid.org/0000-0003-3339-562X

\section{Liting Hu}

Qingdao University Medical College

\section{Wenying Wang}

Qingdao University Medical College

\section{Lina Zhang}

Qingdao University Medical College

\section{Qiulu Chen}

Qingdao University Medical College

Jing Lin

Qingdao University Medical College

Guiqiu Zhao ( $\square$ guiqiu_zhao@126.com )

\section{Research article}

Keywords: Proliferative diabetic retinopathy; Pars plana vitrectomy; Ranibizumab; Triamcinolone acetonide; Intravitreal injection

Posted Date: September 17th, 2019

DOI: https://doi.org/10.21203/rs.2.14561/v1

License: (c) (1) This work is licensed under a Creative Commons Attribution 4.0 International License. Read Full License 


\section{Abstract}

Background: To explore the treatment efficacy of the combination of preoperative intravitreal ranibizumab (IVR) and postoperative intravitreal triamcinolone acetonide (IVTA) in patients undergoing pars plana vitrectomy (PPV) for proliferative diabetic retinopathy (PDR). Methods: A retrospective comparative study was performed on 128 eyes of 128 patients who had PDR and underwent PPV. Patients who received a single PPV were assigned to Group A. Those who received PPV with preoperative IVR were assigned to Group B. Patients in Group C underwent PPV combined preoperative IVR and postoperative IVTA. Intraoperative findings, changes in mean best-corrected visual acuity (BCVA) and postoperative adverse events were retrospectively evaluated at 6-month follow-up. Results: The incidences of iatrogenic breaks, severe intraoperative bleeding, using long-term internal tamponade agents, recurrent vitreous hemorrhage $(\mathrm{VH})$ and duration of surgery were statistically significantly less in Group B and Group C than in Group A. The postoperative BCVA was statistically significantly better in Groups B and Group $C$ than in Group A respectively at 1 month after surgery. The mean 3-month postoperative visual acuity was better in Group C. The incidence of high intraocular pressure (IOP) was significantly higher in Group $\mathrm{C}$ at the first postoperative week. There were no statistically significant differences in the incidence of exudative retinal detachment and choroidal detachment among the three groups. Conclusion: In patients undergoing PPV for PDR, preoperative IVR significantly reduced the occurrence of intraoperative and postoperative complications, and the combination of preoperative IVR and postoperative IVTA can better improve the postoperative visual outcome.

\section{Background}

Proliferative diabetic retinopathy (PDR) is a leading cause of blindness in patients with diabetes. It is characterized by retinal neovascularization, retinal capillary leakage, hemorrhage, and fibrovascular proliferation in the vitreous retinal interface, which results in vitreous hemorrhage $(\mathrm{VH})$ and tractional retinal detachment (TRD)[1]. Fortunately, the advancements in surgical instrumentations and techniques have significantly improved the postoperative anatomical and visual outcomes of patients with PDR now when compared with that in the past, when severe PDR was regarded as an untreatable and blinding condition[2].

Moreover, the introduction of preoperative adjuncts such as anti-vascular endothelial growth factor (VEGF) agents has further reduced the risk of intraoperative and postoperative complications[3, 4]. A preoperative intravitreal injection of the anti-VEGF agent was found to be effective in reducing the incidence of intraoperative and postoperative hemorrhage, shortening the mean surgical time and improving best-corrected visual acuity (BCVA)[5]. At present, the preoperative use of anti-VEGF agent has become a routine way for complicated PDR surgery. 
Diabetic macular edema (DME) is an important reason for low vision in PDR patients. It sometimes persists or recurs in eyes after vitrectomy[6]. Treatment of DME is an important factor in the prognosis of visual acuity in patients with DR. Treatments for DME include laser photocoagulation, sub-Tenon's capsule injection of triamcinolone acetonide (TA), intravitreal injection of triamcinolone acetonide (IVTA), and intravitreal injection of anti-VEGF agents [7-10]. Several studies demonstrated that IVTA is an effective treatment modality and could be incorporated into therapeutic strategies for DME to provide more aggressive treatments with better visual outcomes[11, 12]. Furthermore, the use of combination therapies of anti-VEGF agents and TA is more effective for improving visual acuity and decreasing macular thickness $[12,13]$. After vitrectomy surgery with a preoperative intravitreal anti-VEGF agent, combining with IVTA may be a better choice for PDR.

Previous reports dealing with treatment for DME compared to a variety of anti-VEGF agents with or without IVTA[14]. To our knowledge, there is no study that compares the effectiveness of combining preoperative intravitreal ranibizumab (IVR) and postoperative IVTA for vitrectomy surgery of PDR. The present study focused on the treatment effectiveness and complications of IVR and IVR/IVTA in the perioperative period of PDR.

\section{Methods}

We performed a retrospective comparative study of patients with PDR who had undergone 23-G pars plana vitrectomy (PPV) combined preoperative IVR with or without postoperative IVTA. All of these patients completed at least 6 months of follow-up postoperatively. The protocol was approved by the Ethics Committee, Affiliated Hospital of Qingdao University and complied with the tenets of the Declaration of Helsinki.

Patients with the following criteria were excluded from the study:

1. Patients who received laser photocoagulation or vitreoretinal surgery.

2. Patients who received more than one intravitreal injection of anti-VEGF agent or TA before vitreous surgery.

3. Patients whose preoperative BCVA was less than hand movements.

4. Patients with diabetes with other possible causes of $\mathrm{VH}$ such as vascular occlusions or polypoidal choroidal vasculopathy (PCV).

Between January 2014 and March 2018 at the Affiliated Hospital of Qingdao University, 128 eyes of 128 patients with PDR were enrolled. For patients with binocular surgery, we only chose the first eye to be 
included in this study. 32 eyes of 32 patients who underwent PPV without receiving IVR or IVTA were assigned to the control group (Group A). Subsequently, we divided the rest of the patients into 2 groups. The IVR group consisted of 40 eyes of 40 patients who underwent PPV with preoperative IVR only (Group B). And the IVR/IVTA group consisted of 56 eyes of 56 patients who underwent PPV combined preoperative IVR and postoperative IVTA (Group C).

In all 128 patients, a 3-port 23-G PPV was performed with Stellaris PC platform (Bausch \& Lomb, Rochester, NY, USA) at a speed of 5000 cuts per minute. All patients underwent removal of fibrous tissue, panretinal photocoagulation (PRP), as well as internal tamponade (sterile air, C3F8 gas or silicon oil) wherever required. For the IVR group, the dose of intravitreally injected ranibizumab (Lucentis; Genentech Inc., South San Francisco, CA) was $0.5 \mathrm{mg} / 0.05 \mathrm{~mL}$. For the IVR/IVTA group, $0.5 \mathrm{mg}$ of ranibizumab and 2 mg of TA (Jida, Kunming, Yunnan, CHN) were used. All patients in the IVR group and IVR/IVTA group underwent PPV within 1 week after the IVR. Intraoperative factors such as hemorrhage, iatrogenic breaks, type of internal tamponade and the duration of surgery were noted. Postoperative record included BCVA, intraocular pressure (IOP), postoperative $\mathrm{VH}$, postoperative exudative detachment of the retina and postoperative choroidal detachment.

For statistical analysis, the categorical variables were expressed as rates or proportions and were compared using the Chi-square Test; One-way Analysis of Variance (ANOVA) and Least Significant Difference (LSD) test was used to evaluate differences in parametric variables. A $P$ value $<0.05$ was considered statistically significant.

\section{Results}

\section{Baseline Data}

The baseline features of all cases are summarized in Table 1. Patient characteristics were not significantly different in the three groups. Grading of the extent of fibrovascular proliferation was defined as follows[15]: Grade 1, focal adhesions only; Grade 2, broad adhesion $\geq 1$ sites or vitreous-retinal adhesion at disk, macula or arcade; Grade 3, vitreous-retinal attachment extending to the periphery.

\section{Intraoperative findings}

Surgical findings and additional surgical procedures are shown in Table 2.

The incidence of iatrogenic retinal breaks was comparable in the three groups respectively, and it was statistically significantly less in Group B and Group C than in Group A ( $P=0.015$ and 0.028 , respectively, 
Chi-square Test). Intraoperative bleeding was classified into 3 grades[15]: Grade 1, minor bleeding that stopped either spontaneously or by transient bottle elevation; Grade 2, moderate bleeding requiring endodiathermy or with formation of broadsheets of clots extending away from the bleeding site; Grade 3, thick clot formation covering at least half of the posterior pole or interfering with the surgical plane. There was a significant difference in the severity of intraoperative bleeding among the three groups $(P=0.019$, Chi-square Test). The incidence of severe intraoperative bleeding was statistically significantly less in Group B $(P=0.020)$ and Group C $(P=0.011)$ than in Group A. There was no significant difference between the Group $B$ and Group $C(P=0.975)$. The type of internal tamponading agent was comparable in the three groups. The use of long-term internal tamponade agents (C3F8 and silicon oil) were statistically significant in three groups ( $P=0.003$, Chi-square Test), which is less in Group B and Group $C$ than in Group A $(P=0.028$ and 0.000 , respectively). Additionally, the data showed that the mean surgical time was statistically significantly shorter in Group B and Group C than in Group A ( $P=0.000$ and 0.000 , respectively, ANOVA and LSD test).

\section{Visual Acuity}

BCVA was converted from Snellen chart values to the logarithm of minimum angle of resolution (logMAR) equivalent units for statistical calculations. As shown in Table 3, at baseline examination, the mean BCVA was $1.567 \pm 0.340 \log M A R, 1.555 \pm 0.343 \log M A R$, and $1.587 \pm 0.340 \log M A R$ respectively in groups $A, B$, and $C$. There was no statistically significant difference between the three groups $(P=0.893$, ANOVA and LSD test). At the 1-month follow-up, the mean BCVA had increased to 1.250 \pm 0.398 logMAR in group $A, 0.946 \pm 0.365 \log M A R$ in Group $B$, and $0.872 \pm 0.416 \log M A R$ in Group $C$. The postoperative mean BCVA was statistically significantly better in Groups B $(P=0.002)$ and Group $C(P=0.000)$ than in Group A respectively at 1 month after surgery. There was no significant difference between Group $B$ and Group $C$ $(P=0.371)$. The 3-month postoperative BCVA was not significantly different between Groups $\mathrm{A}$ and Group B $(P=0.083)$. However, Group $C$ had better visual acuity than Group A $(P=0.000)$ and Group B $(P=0.044)$ respectively. 6 months after surgery, visual acuities were not significantly different among the three groups $(P=0.155)$.

\section{Postoperative adverse events}

The primary postoperative adverse events, recorded in Table 4, were high IOP and the incidence of early recurrent $\mathrm{VH}$.

A transient ( $<1$ week) increase in IOP $(>25 \mathrm{mmHg}$ ) occurred in 4 patients, 5 patients and 17 patients in Group A, B, C respectively. After one month of surgery, the patients with high IOP decreased to 2, 1 and 3 respectively. Analysis of these data showed a statistically significant increase in Group C compared with 
Group A and B at 1 week after surgery ( $P=0.045$, Chi-square Test). There was no difference at 1 month $(P=0.719)$.

VH was scaled according to the Diabetic Retinopathy Vitrectomy Study grading system 1 week and 1 month after surgery. Grade 0: No VH; Grade 1: Mild VH with visible fundus details; Grade 2: Moderate VH with no visible fundus details but with an orange fundus reflex; Grade 3: Severe VH with no retinal details and no orange fundus reflex. The incidence of $\mathrm{VH}$ was significantly higher in Group $\mathrm{A}$ than that in Group $\mathrm{B}(P=0.040$, Chi-square Test) and Group C $(P=0.019)$ within 1 month after the operation. No significant difference was observed between Group B and Group $C(P=0.947)$.

\section{Postoperative exudative retinal detachment and choroidal detachment}

Exudative retinal detachment and choroidal detachment are relatively rare postoperative complications for the patients with PDR, mostly due to excessive laser energy [16]. We observed the effect of IVTA on exudative reticular detachment and choroidal detachment to clarify whether TA had the effect of reducing these complications. However, there were no statistically significant differences in the incidence of exudative retinal detachment $(P=0.659$, Chi-square Test $)$ and choroidal detachment $(P=0.261)$ among the three groups (Table 5).

\section{Discussion}

In the clinical treatment of PDR, the injection of anti-VEGF agents into the vitreous body and the intravitreal and/or sub-Tenon injection of TA have become popular, in addition to retinal photocoagulation and vitrectomy procedures[17].

Several pieces of evidence indicated that the growth of new vessels from the retina or optic nerve is likely a result of the release of VEGF into the vitreous cavity as a response to ischemia[18-20]. Ranibizumab, as a recombinant humanized monoclonal VEGF antibody, has increasingly been used to treat PDR. Many clinical trials proved that IVR pretreatment ameliorates fundus conditions before vitrectomy[3,21]. This study also shows that IVR is helpful in facilitating vitrectomy in severe PDR. IVR has a significant effect in reducing surgical complications, such as iatrogenic retinal breaks and severe intraoperative bleeding, through facilitating removal of the fibrovascular membranes and the regression of neovascularization. Due to less retinal breaks, sterile air and C3F8 become the main types of internal tamponading agent, instead of silicone oil. In addition, the chance of postoperative complication such as re-bleeding was decreased after IVR because of preoperative regression of the vascular component. The IVR+IVTA group has the same performance as the IVR group in the above aspects. 
Studies have demonstrated a reduction in VEGF levels after successful laser treatment of PDR[22]. The postoperative inflammation is one of the major causes of postoperative complications, such as exudative retinal detachment[16] and proliferative vitreoretinopathy. The postoperative inflammatory cells can secrete varieties of chemical mediators and cytokines, which stimulate the invasion of secondary inflammatory cells into the vitreoretinal tissue[21]. IVTA is a logical strategy to prevent postoperative complications because of its anti-inflammatory, antiangiogenic, and blood-retinal barrier stabilizing effects[21, 23].

In the present study, we confirmed the role of postoperative IVTA based on preoperative IVR for vitrectomy surgery of PDR. The BCVA was comparable among the three groups and the postoperative BCVA was significantly improved within each group. It was shown that preoperative IVR with or without postoperative IVTA could improve the BCVA at 1 month. The BCVA improvement at 3 months was significantly superior in the IVR/IVTA group compared with the IVR group. But at 6 months, the differences of BCVA among three groups had no significance. Study has confirmed that TA has a longer half-life than ranibizumab, and its anti-inflammatory effect persists for as long as 3 months after injection [12]. This may be the main reason why the combination group had better vision at 3 months.

Studies have suggested that proliferation of pro-inflammatory cytokines, such as IL-6, was found after PRP, causing blood-retinal barrier dysfunction[24] and increasing permeability[25], and resulting in exudative retinal detachment [16], which was often accompanied by varying degrees of exudative choroidal detachment. In the present study, exudative retinal detachment often presents in patients with BSS or sterile air tamponade at each group. Although the mechanisms of postoperative exudative retinal detachment is not clear, we would have liked to confirm that IVTA will be useful to reduce exudative retinal detachment and choroidal detachment through anti-inflammatory effects. Unfortunately, our study revealed IVTA has no significant effect on the prevention of exudative retinal detachment and choroidal detachment at 1 week after surgery.

When using TA, another problem that cannot be ignored is IOP. IOP increases did not show significant differences between the control and IVR groups, but both were significantly different from the IVTA group in a short time after surgery. More patients had transient higher postoperative IOP in the IVTA group. However, most patients with high IOP can tend to be normal after ocular hypotensive treatment. 


\section{Conclusions}

It seems to be a promising treatment that combining preoperative IVR and postoperative IVTA for vitrectomy surgery of PDR, minimizing the risk for decreased vision. Postoperative IVTA is an effective adjuvant to preoperative intravitreal injection of anti-VEGF agents for vitrectomy of PDR.

\section{Abbreviations}

IVR intravitreal ranibizumab

IVTA intravitreal triamcinolone acetonide

PPV pars plana vitrectomy

PDR proliferative diabetic retinopathy

BCVA best-corrected visual acuity

IOP intraocular pressure

VH vitreous hemorrhage

TRD tractional retinal detachment

VEGF vascular endothelial growth factor

DME diabetic macular edema

TA triamcinolone acetonide

PCV polypoidal choroidal vasculopathy

PRP panretinal photocoagulation

ANOVA One-way Analysis of Variance

LSD Least Significant Difference

\section{Declarations}

Ethics approval and consent to participate

This study followed the tenets of the Declaration of Helsinki and was approved by the Ethics Committee, Affiliated Hospital of Qingdao University. All patients provided written consent to participate in the study. 
Consent for publication

Not applicable.

Availability of data and material

The datasets used and/or analyzed during the current study are available from the corresponding author upon reasonable request.

Competing interests

The authors declare that they have no competing interests.

Funding

This study was supported by Natural Science Foundation of Shandong Province (No. ZR2017MH055), National Natural Science Foundation of China (No. 81900824), the "Clinical Medicine + X" Engineering Research Project of Qingdao University Medical College and the Young Investigator Fund of Affiliated Hospital, Qingdao University.

Authors' contributions

All authors (ZD, LH, WW, LZ, QC, JL, GZ) contributed to the conception and design of the study. ZD and LH were responsible for the acquisition, analysis, interpretation of data and were major contributors in writing the manuscript. All authors (ZD, LH, WW, LZ, QC, JL, GZ) have been involved in revising and giving the final approval of the version to be published. All authors read and approved the final manuscript.

Acknowledgements

Not applicable

\section{References}

1. Fong DS, Aiello LP, Ferris FL, 3rd, Klein R: Diabetic retinopathy. Diabetes Care 2004, 27(10):25402553. 
2. Sharma T, Fong A, Lai TY, Lee V, Das S, Lam D: Surgical treatment for diabetic vitreoretinal diseases: a review. Clin Exp Ophthalmol 2016, 44(4):340-354.

3. Guan G, Zang J: Meta-analysis of the effect of perioperative injection of Lucentis on intraoperative bleeding in patients with proliferative diabetic retinopathy. Eye Sci 2015, 30(4):171-175.

4. Hernandez-Da Mota SE, Nunez-Solorio SM: Experience with intravitreal bevacizumab as a preoperative adjunct in 23-G vitrectomy for advanced proliferative diabetic retinopathy. Eur $J$ Ophthalmol 2010, 20(6):1047-1052.

5. Zhao LQ, Zhu H, Zhao PQ, Hu YQ: A systematic review and meta-analysis of clinical outcomes of vitrectomy with or without intravitreal bevacizumab pretreatment for severe diabetic retinopathy. $\mathrm{Br} J$ Ophthalmol 2011, 95(9):1216-1222.

6. Romano V, Angi M, Scotti F, del Grosso R, Romano D, Semeraro F, Vinciguerra P, Costagliola C, Romano MR: Inflammation and macular oedema after pars plana vitrectomy. Mediators Inflamm 2013, 2013:971758.

7. Romero-Aroca P: Current status in diabetic macular edema treatments. World J Diabetes 2013, 4(5):165-169.

8. Nonomura S, Oshitari T, Arai M, Sato E, Takatsuna Y, Baba T, Yamamoto S: The effect of posterior sub-Tenon's capsule triamcinolone acetonide injection to that of pars plana vitrectomy for diabetic macular edema. Clin Ophthalmol 2014, 8:825-830.

9. Jonas JB, Kamppeter BA, Harder B, Vossmerbaeumer U, Sauder G, Spandau UH: Intravitreal triamcinolone acetonide for diabetic macular edema: a prospective, randomized study. J Ocul Pharmacol Ther 2006, 22(3):200-207.

10. Gillies MC, Sutter FK, Simpson JM, Larsson J, Ali H, Zhu M: Intravitreal triamcinolone for refractory diabetic macular edema: two-year results of a double-masked, placebo-controlled, randomized clinical trial. Ophthalmology 2006, 113(9):1533-1538.

11. Lim JW, Lee HK, Shin MC: Comparison of intravitreal bevacizumab alone or combined with triamcinolone versus triamcinolone in diabetic macular edema: a randomized clinical trial. Ophthalmologica 2012, 227(2):100-106.

12. Jin E, Luo L, Bai Y, Zhao M: Comparative effectiveness of intravitreal bevacizumab with or without triamcinolone acetonide for treatment of diabetic macular edema. Ann Pharmacother 2015, 49(4):387-397.

13. Ahmadieh H, Ramezani A, Shoeibi N, Bijanzadeh B, Tabatabaei A, Azarmina M, Soheilian M, Keshavarzi G, Mohebbi MR: Intravitreal bevacizumab with or without triamcinolone for refractory diabetic macular edema; a placebo-controlled, randomized clinical trial. Graefes Arch Clin Exp Ophthalmol 2008, 246(4):483-489.

14. Wang YS, Li X, Wang HY, Zhang ZF, Li MH, Su XN: Intravitreal bevacizumab combined with/without triamcinolone acetonide in single injection for treatment of diabetic macular edema. Chin Med $J$ (Engl) 2011, 124(3):352-358. 
15. Yang $\mathrm{CM}$, Yeh $\mathrm{PT}$, Yang $\mathrm{CH}$, Chen MS: Bevacizumab pretreatment and long-acting gas infusion on vitreous clear-up after diabetic vitrectomy. Am J Ophthalmol 2008, 146(2):211-217.

16. Sun DF, Wang YL, Wang B, Xu CL, Zhang G, Li J, Zhang XM: Predictive risk factors for exudative retinal detachment after vitrectomy for proliferative diabetic retinopathy. Medicine (Baltimore) 2019, 98(8):e14603.

17. Suzuki Y, Suzuki K, Yokoi Y, Miyagawa Y, Metoki T, Nakazawa M: Effects of intravitreal injection of bevacizumab on inflammatory cytokines in the vitreous with proliferative diabetic retinopathy. Retina 2014, 34(1):165-171.

18. Adamis AP, Miller JW, Bernal MT, D'Amico DJ, Folkman J, Yeo TK, Yeo KT: Increased vascular endothelial growth factor levels in the vitreous of eyes with proliferative diabetic retinopathy. $A m \mathrm{~J}$ Ophthalmol 1994, 118(4):445-450.

19. Aiello LP, Avery RL, Arrigg PG, Keyt BA, Jampel HD, Shah ST, Pasquale LR, Thieme H, Iwamoto MA, Park JE et al: Vascular endothelial growth factor in ocular fluid of patients with diabetic retinopathy and other retinal disorders. N Engl J Med 1994, 331(22):1480-1487.

20. Pe'er J, Shweiki D, Itin A, Hemo I, Gnessin H, Keshet E: Hypoxia-induced expression of vascular endothelial growth factor by retinal cells is a common factor in neovascularizing ocular diseases. Lab Invest 1995, 72(6):638-645.

21. Cui J, Chen H, Lu H, Dong F, Wei D, Jiao Y, Charles S, Gu W, Wang L: Efficacy and Safety of Intravitreal Conbercept, Ranibizumab, and Triamcinolone on 23-Gauge Vitrectomy for Patients with Proliferative Diabetic Retinopathy. J Ophthalmol 2018, 2018:4927259.

22. Zhang X, Saaddine JB, Chou CF, Cotch MF, Cheng YJ, Geiss LS, Gregg EW, Albright AL, Klein BE, Klein R: Prevalence of diabetic retinopathy in the United States, 2005-2008. Jama 2010, 304(6):649-656.

23. Sakamoto T, Miyazaki M, Hisatomi T, Nakamura T, Ueno A, Itaya K, Ishibashi T: Triamcinoloneassisted pars plana vitrectomy improves the surgical procedures and decreases the postoperative blood-ocular barrier breakdown. Graefes Arch Clin Exp Ophthalmol 2002, 240(6):423-429.

24. Desai TR, Leeper NJ, Hynes KL, Gewertz BL: Interleukin-6 causes endothelial barrier dysfunction via the protein kinase C pathway. J Surg Res 2002, 104(2):118-123.

25. Maruo N, Morita I, Shirao M, Murota S: IL-6 increases endothelial permeability in vitro. Endocrinology 1992, 131(2):710-714.

\section{Tables}

Table 1. Baseline features of patients with PDR 


\begin{tabular}{|c|c|c|c|c|}
\hline Characteristics & $\begin{array}{l}\text { Group A } \\
(\mathrm{n}=32)\end{array}$ & $\begin{array}{c}\text { Group B } \\
(\mathrm{n}=40) \\
\end{array}$ & $\begin{array}{c}\text { Group C } \\
(\mathrm{n}=56) \\
\end{array}$ & $P$ \\
\hline Age (years) (mean \pm SD) & $58.313 \pm 6.229$ & $59.475 \pm 6.869$ & $58.570 \pm 6.610$ & 0.576 \\
\hline Sex & & & & 0.962 \\
\hline Male & 11 & 15 & 20 & \\
\hline Female & 21 & 25 & 36 & \\
\hline Duration of DM (n) & & & & 0.786 \\
\hline$<10$ years & 8 & 11 & 12 & \\
\hline$>10$ years & 24 & 29 & 44 & \\
\hline Treatment regimen for DM (n) & & & & 0.850 \\
\hline No insulin & 5 & 8 & 9 & \\
\hline Insulin & 27 & 32 & 47 & \\
\hline \multicolumn{5}{|c|}{ Extent of fibrovascular proliferation [n (\%)] } \\
\hline Grade 1 & 4 & 7 & 9 & \\
\hline Grade 2 & 23 & 28 & 39 & \\
\hline Grade 3 & 5 & 5 & 8 & \\
\hline Systemic hypertension (n) & 24 & 32 & 37 & 0.302 \\
\hline Renal insufficiency (n) & 6 & 9 & 11 & 0.913 \\
\hline Hemodialysis (n) & 5 & 4 & 7 & 0.773 \\
\hline Lens status (n) & & & & 0.739 \\
\hline Phakic eye & 27 & 31 & 46 & \\
\hline Pseudophakic eye & 5 & 9 & 10 & \\
\hline
\end{tabular}

$P<0.05$ was considered statistically significant.

SD, standard deviation; DM, diabetes mellitus.

Table 2. Surgical Procedures and Operative Findings for Patients with PDR

\begin{tabular}{|c|c|c|c|c|}
\hline Surgical Procedures and Findings & $\begin{array}{l}\text { Group A } \\
(\mathrm{n}=32)\end{array}$ & $\begin{array}{l}\text { Group B } \\
(\mathrm{n}=40)\end{array}$ & $\begin{array}{l}\text { Group C } \\
(\mathrm{n}=56)\end{array}$ & $P$ \\
\hline Iatrogenic breaks (n[\%]) & 16 & 9 & 15 & 0.028 \\
\hline Intraoperative bleeding $(\mathrm{n}[\%])$ & & & & 0.019 \\
\hline Grade 1 & 2 & 8 & 12 & \\
\hline Grade 2 & 19 & 28 & 38 & \\
\hline Grade 3 & 11 & 4 & 6 & \\
\hline Type of internal tamponade (n[\%]) & & & & 0.011 \\
\hline Balanced salt solution (BSS) & 3 & 7 & 10 & \\
\hline Sterile air & 5 & 17 & 28 & \\
\hline C3F8 & 8 & 6 & 4 & \\
\hline Silicon oil & 16 & 10 & 14 & \\
\hline Duration of surgery([mean \pm SD] [minutes]) & $119.469 \pm 28.267$ & $83.525 \pm 24.541$ & $87.179 \pm 19.919$ & 0.000 \\
\hline
\end{tabular}


$P<0.05$ was considered statistically significant.

SD, standard deviation

Table 3. Visual Acuity at Preoperative and Postoperative in Patients with PDR (mean \pm SD)

\begin{tabular}{ccccc}
\hline Visual Acuity & Group A & Group B & Group C & $P$ \\
& $(\mathrm{n}=32)$ & $(\mathrm{n}=40)$ & $(\mathrm{n}=56)$ & \\
\hline Preoperative & $1.567 \pm 0.340$ & $1.555 \pm 0.343$ & $1.587 \pm 0.340$ & 0.893 \\
1-month postoperative & $1.250 \pm 0.398$ & $0.946 \pm 0.365$ & $0.872 \pm 0.416$ & 0.000 \\
3-month postoperative & $1.123 \pm 0.393$ & $0.961 \pm 0.375$ & $0.798 \pm 0.396$ & 0.001 \\
6-month postoperative & $1.148 \pm 0.401$ & $1.000 \pm 0.405$ & $0.968 \pm 0.458$ & 0.155 \\
\hline
\end{tabular}

$P<0.05$ was considered statistically significant.

Table 4. Postoperative adverse events in Patients with PDR

\begin{tabular}{lcccc}
\hline \multicolumn{1}{c}{ Adverse Events } & $\begin{array}{c}\text { Group A } \\
(\mathrm{n}=32)\end{array}$ & $\begin{array}{c}\text { Group B } \\
(\mathrm{n}=40)\end{array}$ & $\begin{array}{c}\text { Group C } \\
(\mathrm{n}=56)\end{array}$ & $P$ \\
\hline $\begin{array}{l}\text { High intraocular pressure } \\
\text { 1-week postoperative }\end{array}$ & 4 & 5 & 17 & 0.045 \\
1-month postoperative & 2 & 1 & 3 & 0.719 \\
Recurrent vitreous hemorrhage & & & & 0.026 \\
Grade 1 & 6 & 2 & 4 & \\
Grade 2 & 1 & 1 & 0 & \\
Grade 3 & 1 & 0 & 0 & \\
\hline
\end{tabular}

$P<0.05$ was considered statistically significant.

Table 5. Postoperative exudative retinal detachment and choroidal detachment in Patients with PDR

\begin{tabular}{lccccc}
\hline & Group A & Group B & Group C & $P$ \\
& $(\mathrm{n}=32)$ & $(\mathrm{n}=40)$ & $(\mathrm{n}=56)$ & \\
\hline Exudative retinal detachment & 4 & 3 & 4 & 0.659 \\
Exudative choroidal detachment & 6 & 5 & 4 & 0.261 \\
\hline
\end{tabular}

$P<0.05$ was considered statistically significant. 